\title{
Front Matter: Volume 11182
}

, "Front Matter: Volume 11182," Proc. SPIE 11182, Semiconductor Lasers and Applications IX, 1118201 (20 November 2019); doi: 10.1117/12.2560383

SPIE. Event: SPIE/COS Photonics Asia, 2019, Hangzhou, China 


\title{
PROCEEDINGS OF SPIE
}

\section{Semiconductor Lasers and Applications IX}

\author{
Ning Hua Zhu \\ Werner H. Hofmann \\ Jian-Jun He \\ Editors
}

\section{1-23 October 2019 \\ Hangzhou, China}

Sponsored by

SPIE

COS-Chinese Optical Society

\section{Cooperating Organizations}

Tsinghua University (China) • Peking University (China) • University of Science and Technology of China (China) • Zhejiang University (China) - Tianjin University (China) - Beijing Institute of Technology (China) • Beijing University of Posts and Telecommunications (China) • Nankai University (China) • Changchun University of Science and Technology (China) University of Shanghai for Science and Technology (China) - Capital Normal University (China) • Huazhong University of Science and Technology (China) • Beijing Jiaotong University (China) • China Jiliang University (China) • Shanghai Institute of Optics and Fine Mechanics, CAS (China) - Changchun Institute of Optics, Fine Mechanics and Physics, CAS (China) Institute of Semiconductors, CAS (China) • Institute of Optics and Electronics, CAS (China) • Institute of Physics, CAS (China) Shanghai Institute of Technical Physics, CAS (China) • China Instrument and Control Society (China) • Japan Optical Society (Japan) • Korea Optical Society (Korea, Republic of) - Australia Optical Society (Australia) • Singapore Optical Society (Singapore) • European Optical Society

Supporting Organizations

China Association for Science and Technology (CAST)

Department of Information of National Nature Science Foundation, China (NSFC)

Published by

SPIE

\section{Volume 11182}


The papers in this volume were part of the technical conference cited on the cover and title page. Papers were selected and subject to review by the editors and conference program committee. Some conference presentations may not be available for publication. Additional papers and presentation recordings may be available online in the SPIE Digital Library at SPIEDigitallibrary.org.

The papers reflect the work and thoughts of the authors and are published herein as submitted. The publisher is not responsible for the validity of the information or for any outcomes resulting from reliance thereon.

Please use the following format to cite material from these proceedings:

Author(s), "Title of Paper," in Semiconductor Lasers and Applications IX, edited by Ning Hua Zhu, Werner H. Hofmann, Jian-Jun He, Proceedings of SPIE Vol. 11182 (SPIE, Bellingham, WA, 2019) Sevendigit Article CID Number.

ISSN: 0277-786X

ISSN: 1996-756X (electronic)

ISBN: 9781510630819

ISBN: 9781510630826 (electronic)

Published by

SPIE

P.O. Box 10, Bellingham, Washington 98227-0010 USA

Telephone +1 3606763290 (Pacific Time) · Fax + 13606471445

SPIE.org

Copyright @ 2019, Society of Photo-Optical Instrumentation Engineers.

Copying of material in this book for internal or personal use, or for the internal or personal use of specific clients, beyond the fair use provisions granted by the U.S. Copyright Law is authorized by SPIE subject to payment of copying fees. The Transactional Reporting Service base fee for this volume is $\$ 21.00$ per article (or portion thereof), which should be paid directly to the Copyright Clearance Center (CCC), 222 Rosewood Drive, Danvers, MA 01923. Payment may also be made electronically through CCC Online at copyright.com. Other copying for republication, resale, advertising or promotion, or any form of systematic or multiple reproduction of any material in this book is prohibited except with permission in writing from the publisher. The CCC fee code is 0277$786 \times / 19 / \$ 21.00$.

Printed in the United States of America by Curran Associates, Inc., under license from SPIE.

Publication of record for individual papers is online in the SPIE Digital Library.

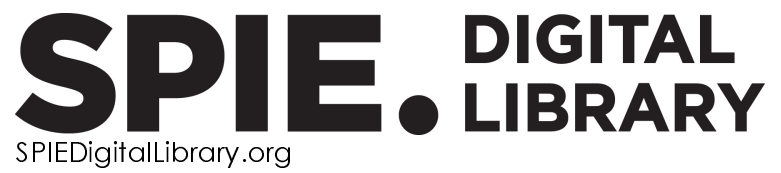

Paper Numbering: Proceedings of SPIE follow an e-First publication model. A unique citation identifier (CID) number is assigned to each article at the time of publication. Utilization of CIDs allows articles to be fully citable as soon as they are published online, and connects the same identifier to all online and print versions of the publication. SPIE uses a seven-digit CID article numbering system structured as follows:

- The first five digits correspond to the SPIE volume number.

- The last two digits indicate publication order within the volume using a Base 36 numbering system employing both numerals and letters. These two-number sets start with $00,01,02,03,04$, 05, 06, 07, 08, 09, OA, OB ... 0Z, followed by 10-1Z, 20-2Z, etc. The CID Number appears on each page of the manuscript. 


\title{
Contents
}

\author{
vii Authors \\ ix Symposium Committees \\ xiii Conference Committee
}

SESSION 1 INTEGRATED OPTOELECTRONIC DEVICES I

$1118202 \quad$ Electro-absorption modulated tunable V-cavity laser (Invited Paper) [1 $1182-1]$

1118204 Design and simulation of an anti-symmetric Bragg grating silicon modulator [1 $1182-3]$

SESSION 2 INTEGRATED OPTOELECTRONIC DEVICES II

1118206 Silicon-plus photonic devices for on-chip light-manipulation and photodetection (Invited Paper) [1 $11182-5]$

$1118207 \quad$ 1550nm monolithic MOPA diode laser for lidar applications [1 $1182-6$ ]

$1118208 \quad$ Optically-pumped InAs/GaAs quantum-dot microdisk lasers monolithically grown on on-axis Si (001) substrate [1 $11182-7]$

SESSION $3 \quad$ SUBSYSTEMS USING LASER DIODES

11182 0A Phase shifter and phase response of PD in phased-array antennas (Invited Paper) [11182-9]

11182 OB Photonic generation and transmission of phase-modulated microwave signals (Invited Paper) [11182-10]

11182 OC Development of a 780nm narrow line width semiconductor laser device [11182-11]

SESSION $4 \quad$ APPLICATIONS OF LASER DIODES I

11182 OF High-power low-smile vertically-stacked laser diode based on microchannel cooling [11 182-14]

11182 OG Realization of beam shaping using VCSEL incorporating a high-contrast subwavelength grating [11 182-19] 
111820 3D NIR laser night vision based on gated range-intensity correlation imaging (Invited Paper) [11 1 182-17]

\section{SESSION 6 SEMICONDUCTOR LASERS}

11182 OK Self-recirculating modulation-enhanced optical frequency comb generation pumped by optical injection (Invited Paper) [1 11 1 82 -20]

$11182 \mathrm{OL} \quad$ Performance of high-power diode lasers operated at cryogenic temperature [11182-21]

11182 OM On-chip optical narrowband reflector based on anti-symmetric Bragg grating [11182-22]

11182 ON Narrow linewidth parallel hybrid-integrated optical injection locking DFB laser [1 $1182-23]$

SESSION $7 \quad$ VCSELS I

1118200 Design of 940-nm VCSEL with metastructure (Invited Paper) [1 $1182-24]$

11182 OP $\quad 100 \mathrm{~Gb} / \mathrm{s}$ VCSEL based optical interconnects enabled by multimode full-link optimization (Invited Paper) [1 11 182-25]

\section{SESSION $8 \quad$ VCSELS II}

11182 OR Investigation of thermal performance of small oxide-aperture vertical-cavity surface-emitting lasers (Invited Paper) [1 $11182-28]$

\section{POSTER SESSION}

11182 OU Synchronized random bit generation based on vertical-cavity surface-emitting lasers with optical injection and polarization-rotated feedback [1 $11182-15]$

$111820 \mathrm{~V} \quad$ Monolithic integration of tunable V-coupled-cavity laser and Mach-Zehnder modulator on generic InP platform [1 $11182-31]$

11182 OW High power $685 \mathrm{~nm}$ laser diode array with $300 \mathrm{~W}$ output power and $40 \%$ conversion efficiency [1 $1182-32]$

11182 OX Multiple gas detection using v-cavity coupled diode laser [11182-33] 
11182 OY Incoherent beam combination of mid-wave infrared quantum cascade lasers [11182-34]

$111820 Z \quad$ Blue laser diode light for underwater optical vision guidance in AUV docking [1 $1182-35]$

$1118210 \quad$ Angular velocity measurement system based on optical frequency comb [1 $1182-36]$ 
Proc. of SPIE Vol. $111821118201-6$

Downloaded From: https://www.spiedigitallibrary.org/conference-proceedings-of-spie on 26 Apr 2023 Terms of Use: https://www.spiedigitallibrary.org/terms-of-use 


\section{Authors}

Numbers in the index correspond to the last two digits of the seven-digit citation identifier (CID) article numbering system used in Proceedings of SPIE. The first five digits reflect the volume number. Base 36 numbering is employed for the last two digits and indicates the order of articles within the volume. Numbers start with 00, 01, 02, 03, 04, 05, 06, 07, 08, 09, 0A, OB...0Z, followed by 10-12, 20-2Z, etc.

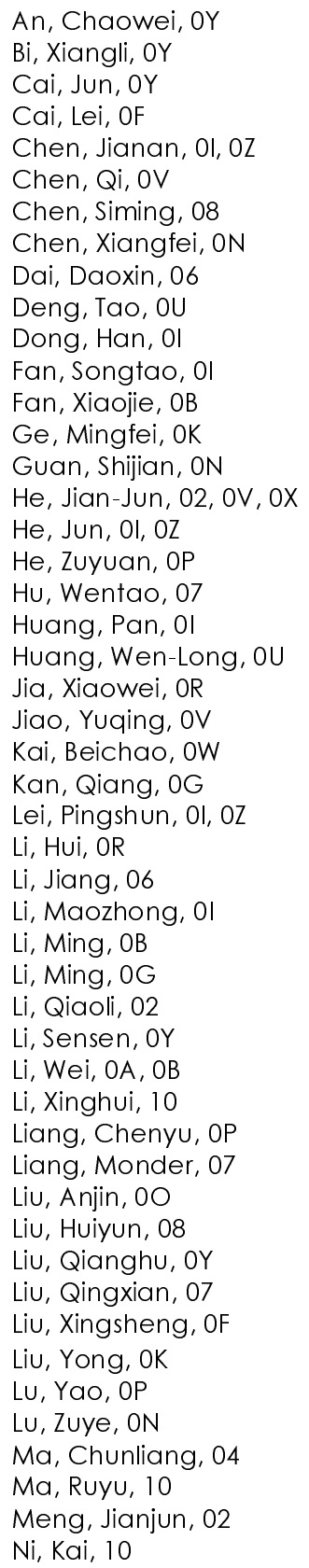

$\mathrm{Nie}$, Zhiqiang, $\mathrm{OL}$

Qi, Zhiqiang, OC

Qiu, Pingping, 0G

Shi, Yuechun, 04, OM

Song, Lijia, 06

Sun, Haocheng, OC

Sun, Jiazheng, OA

Sun, Liang, $\mathrm{Ol}, \mathrm{OZ}$

Sun, Wenhui, OA

Tang, Mingchu, 08

Tang, Xi, OU

Wang, Changsheng, ON

Wang, Chensheng, OC

Wang, Jinnan, OY

Wang, Mingpei, OL

Wang, Shaomeng, OZ

Wang, Xinwei, Ol, OZ

Wang, Xue-Han, OU

Wang, Zhongwen, OV

Wu, Fan, OY

Wu, Fei, OC

Wu, Guanhao, 10

Wu, Yitao, OM

Wu, Zheng-Mao, OU

Wu, Zhuokun, OY

Xia, Guang-Qiong, OU

Xia, Wei, OW

Xia, Yimin, 02

Xiang, Guohong, 08

Xie, Yiyang, $0 G$

$\mathrm{XU}$, Xiangang, OW

$\mathrm{XU}$, Zhongke, $\mathrm{OZ}$ Yan, Xiusheng, OY

Yang, Bo, 00

Yang, Hanting, OX

Yang, Ruiyao, OY

Yang, Wuhao, OL

Yang, Yuqing, $\mathrm{Ol}, \mathrm{OZ}$

Yao, Shuang, OW

Yu, Haoyang, 10

Zah, Chung-en, OF

Zeng, Jie, ON

Zhang, Hongyou, OF

Zhang, Jing, 00

Zhang, Pu, OL

Zhang, Sen, 02

Zhang, Shangjian, OK

Zhang, Wenjia, OP

Zhang, Yali, OK 
Zhang, Yunshan, ON

Zhang, Zhaoyu, 08

Zhang, Zhiyao, OK

Zhao, Jiasheng, 02

Zhao, Yong, OM

Zhong, Xin, Ol

Zhou, Guanjun, OY

Zhou, Qian, 10

Zhou, Taojie, 08

Zhou, Yan, $\mathrm{Ol}, \mathrm{OZ}$

Zhu, Ning Hua, OA, OB

Zhu, Sha, OB

Zhu, Zhen, OW 


\title{
Symposium Committees
}

\author{
General Chairs
}

Jim M. Oschmann, President, SPIE and Ball Aerospace (United States)

Qihuang Gong, President, Chinese Optical Society and Peking University (China)

General Co-chairs

Guangcan Guo, Past President, Chinese Optical Society and University of Science and Technology of China (China)

Zejin Liu, Vice President, Chinese Optical Society and National University of Defense Technology (China)

Technical Program Chairs

Ruxin Li, Vice President, Chinese Optical Society and Shanghai Institute of Optics and Fine Mechanics (China)

Xingde Li, Johns Hopkins University (United States)

Technical Program Co-chairs

Tianchu Li, National Institute of Metrology (China)

Wei Huang, Northwestern Polytechnical University (China)

Ying Gu, Vice President, Chinese Optical Society and PLA General Hospital (China)

Huilin Jiang, Changchun University of Science and Technology (China)

Wenqing Liu, Vice President, Chinese Optical Society, and Anhui Institute of Optics and Fine Mechanics (China)

Guobin Fan, China Academy of Engineering Physics (China)

Suotang Jia, Vice President, Chinese Optical Society, and Shanxi University (China)

Xiaomin Ren, Vice President, Chinese Optical Society, and Beijing University of Posts and Telecommunications (China)

Secretaries-General

Bo Gu, Deputy Secretary General, Chinese Optical Society (China)

Hong Yang, Deputy Secretary General, Chinese Optical Society and Peking University (China) 
Yan Li, Deputy Secretary General, Chinese Optical Society, and Peking University (China)

Daoxin Dai, Zhejiang University (China)

Local Organizing Committee Chair

Xu Liu, Secretary General, Chinese Optical Society and Zhejiang University (China)

Local Organizing Committee Co-chairs

Jianrong Qiu, Zhejiang University (China)

Daoxin Dai, Zhejiang University (China)

Local Secretaries

Wei Xiong, Chinese Optical Society (China)

Qing Yang, Zhejiang University (China)

Local Organizing Committee

Qing Yang, Zhejiang University (China)

Lan Wu, Zhejiang University (China)

Yaocheng Shi, Zhejiang University (China)

Dong Liu, Zhejiang University (China)

Yungui Ma, Zhejiang University (China)

Ke Si, Zhejiang University (China)

Yang Yang, Zhejiang University (China)

Xinyong Dong, China Jiliang University (China)

Le Wang, China Jiliang University (China)

Fei Tong, Chinese Optical Society (China)

Technical Organizing Committee

Mohammad Hossein Asghari, Loyola Marymount University

(United States) and Tachyonics Inc. (United States)

Pablo Benítez, Universidad Politécnica de Madrid (Spain)

Liangcai Cao, Tsinghua University (China)

P. Scott Carney, University of Rochester (United States)

Benyong Chen, Zhejiang University of Science and Technology

(China)

Hongqiang Chen, GE Global Research (United States)

Daoxin Dai, Zhejiang University (China)

Qionghai Dai, Tsinghua University (China)

Qihuang Gong, Peking University (China)

Ying Gu, Chinese PLA General Hospital (China) 
Guang-Can Guo, University of Science and Technology of China (China)

Byoung Seung Ham, Gwangju Institute of Science and Technology (Korea, Republic of)

Sen Han, University of Shanghai for Science and Technology (China) and Suzhou H\&L Instruments, LLC (China)

Zuyuan He, Shanghai Jiao Tong University (China)

Werner H. Hofmann, Technische Universität Berlin (Germany)

Minghui Hong, National University of Singapore (Singapore)

Bahram Jalali, University of California, Los Angeles (United States)

Satoshi Kawata, Osaka University (Japan)

Baojun Li, Jinan University (China)

Ming Li, Institute of Semiconductors, CAS (China)

Ruxin Li, Shanghai Institute of Optics and Fine Mechanics (China)

Xingde Li, Johns Hopkins University (United States)

Jian Liu, PolarOnyx, Inc. (United States)

Tiegen Liu, Tianjin University (China)

Yongfeng Lu, University of Nebraska-Lincoln (United States)

Qingming Luo, Huazhong University of Science and Technology (China)

Gang-Ding Peng, The University of New South Wales (Australia)

Osamu Matoba, Kobe University (Japan)

Min Qiu, Westlake University (China)

Yuji Sano, ImPACT (Japan)

Yunlong Sheng, Université Laval (Canada)

Kebin Shi, Peking University (China)

Tsutomu Shimura, The University of Tokyo (Japan)

Upendra N. Singh, NASA Langley Research Center (United States)

Michael G. Somekh, Shenzhen University (China)

Yuguo Tang, Suzhou Institute of Biomedical Engineering and

Technology (China)

Masahiko Tani, University of Fukui (Japan)

Limin Tong, Zhejiang University (China)

Kazumi Wada, Massachusetts Institute of Technology (United States)

Yongtian Wang, Beijing Institute of Technology (China)

Rongshi Xiao, Beijing University of Technology (China)

Hongxing $\mathrm{Xu}$, Wuhan University (China)

Jianhua Yao, Zhejiang University of Technology (China)

Toru Yoshizawa, Tokyo University of Agriculture and Technology (Japan) and 3D Associates, Inc. (Japan)

Changyuan Yu, The Hong Kong Polytechnic University (Hong Kong, China)

Xiao-Cong Yuan, Shenzhen University (China)

Cunlin Zhang, Capital Normal University (China)

Song Zhang, Purdue University (United States)

Xi-Cheng Zhang, University of Rochester (United States) 
Xinliang Zhang, Wuhan National Laboratory for Optoelectronics (China)

Xuping Zhang, Nanjing University (China)

Zhenrong Zheng, Zhejiang University (China)

Changhe Zhou, Shanghai Institute of Optics and Fine Mechanics (China)

Zhiping Zhou, Peking University (China)

Dan Zhu, Huazhong University of Science and Technology (China)

Ning Hua Zhu, Institute of Semiconductors, CAS (China) 


\title{
Conference Committee
}

\author{
Conference Chairs
}

Ning Hua Zhu, Institute of Semiconductors (China)

Werner H. Hofmann, Technische Universität Berlin (Germany)

Jian-Jun He, Zhejiang University (China)

Conference Program Committee

Minghua Chen, Tsinghua University (China)

Xiangfei Chen, Nanjing University (China)

Nan Chi, Fudan University (China)

Brian Corbett, Tyndall National Institute (Ireland)

Dawei Di, Zhejiang University (China)

Qianggao Hu, Accelink Technologies Company, Ltd. (China)

Weisheng Hu, Shanghai Jiao Tong University (China)

Yongzhen Huang, Beijing University of Posts and Telecommunications (China)

Jimin Li, Institute of Semiconductors (China)

Ming Li, Institute of Semiconductors (China)

Wei Li, Institute of Semiconductors (China)

Xianjie Li, China Electronics Technology Group Corporation (China)

Ning Liu, Huawei Technologies Company, Ltd. (China)

Wenhan Liu, University of Science and Technology of China (China)

Yong Liu, University of Electronic Science and Technology of China (China)

Xiaoyu Ma, Institute of Optics and Electronics (China)

Frank Hudson Peters, Tyndall National Institute (Ireland)

Edwin Y. Pun, City University of Hong Kong (Hong Kong, China)

Hong-Bo Sun, Jilin University (China)

Ji Wang, Changchun Institute of Optics, Fine Mechanics and Physics (China)

Shawn Wang, Luxtera, Inc. (United States)

Yixin Wang, Institute for Infocomm Research (Singapore)

Guang-Qiong Xia, Southwest University (China)

Kun Xu, Beijing University of Posts and Telecommunications (China)

Zhaowen XU, Institute for Infocomm Research (Singapore)

Lianshan Yan, Southwest Jiaotong University (China)

Jinlong Yu, Tianjin University (China)

Siyuan Yu, University of Bristol (United Kingdom)

Li Zeng, Huawei Technologies Company, Ltd. (China)

Baoping Zhang, Xiamen University (China)

Guo-yi Zhang, Peking University (China) 
Shangjian Zhang, University of Electronic Science and Technology of China (China)

Xinliang Zhang, Wuhan National Laboratory for Optoelectronics (China)

Zhiping Zhou, Peking University (China)

Xihua Zou, Southwest Jiaotong University (China)

\section{Session Chairs}

1 Integrated Optoelectronic Devices I

Zhaoyu Zhong, Chinese University of Hong Kong, Shenzhen (China)

2 Integrated Optoelectronic Devices II

Jian-Jun He, Zhejiang University (China)

3 Subsystems Using Laser Diodes

Haohai Yu, Shandong University (China)

4 Applications of Laser Diodes I

Yitang Dai, Beijing University of Posts and Telecommunications (China)

5 Applications of Laser Diodes II

Yali Zhang, University of Electronic Science and Technology of China (China)

6 Semiconductor Lasers

Shilong Pan, Nanjing University of Aeronautics and Astronautics (China)

7 VCSELS I

Hui Li, Qingdao University of Science and Technology (China)

8 VCSELS II

Anjin Liu, Institute of Semiconductors, CAS (China) 